\title{
Implementation of a peer-mediated health education model in the United Arab Emirates: addressing risky behaviours among expatriate adolescents
}

Zachary D. Stanley ${ }^{7^{*}}$, Leena W. Asfour ${ }^{2 *}$, Michael Weitzman ${ }^{3,5,6}$ and Scott E. Sherman ${ }^{4,5}$

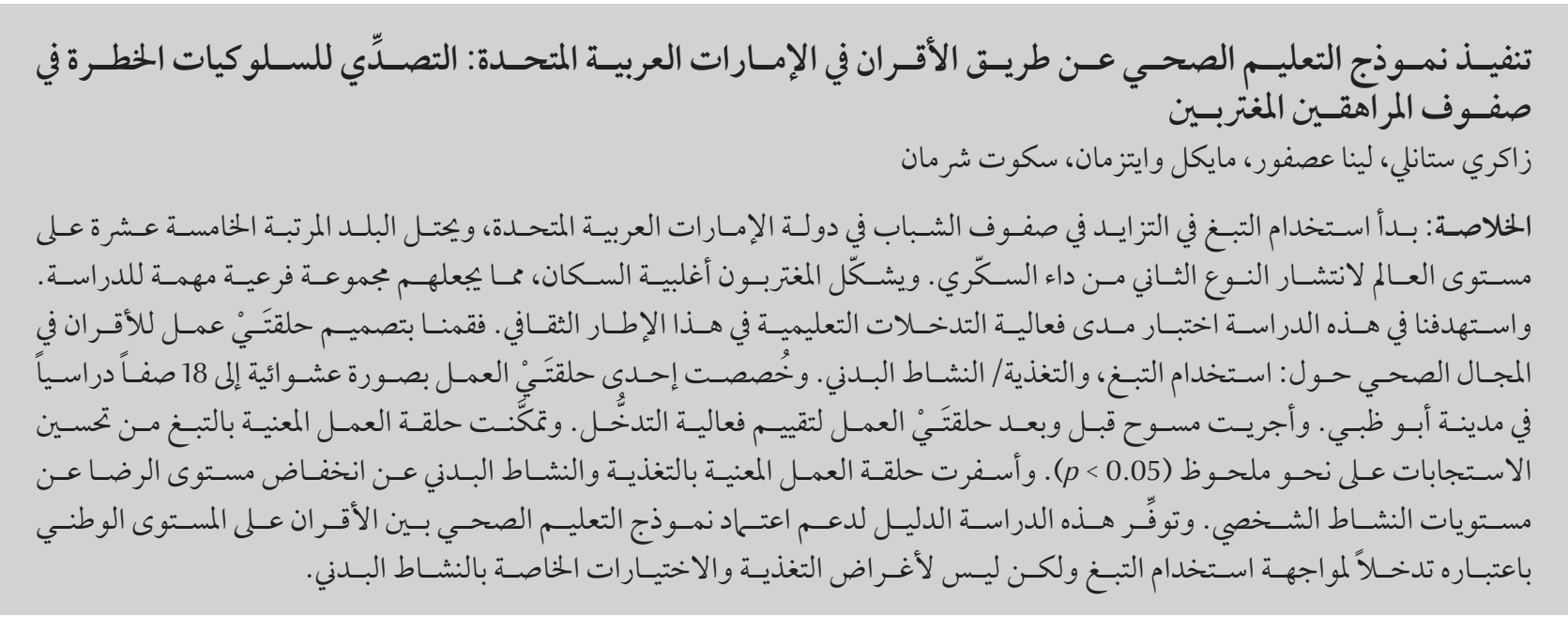

ABSTRACT Tobacco use among young people is increasing in the United Arab Emirates, and the country is ranked 15th in the world for prevalence of type II diabetes. Expatriates comprise a majority of the population, making them an important subset to study. We aimed to test whether an educational intervention would be effective in this cultural setting. We designed 2 peer-to-peer health workshops: tobacco use and nutrition/physical activity. One workshop was randomly assigned to 18 classrooms in private schools in Abu Dhabi. Surveys were administered before and after the workshops to assess intervention effectiveness. The tobacco workshop significantly improved responses $(P<0.05)$. The nutrition and physical activity workshop resulted in decreased satisfaction with personal activity levels. This study provides evidence to support the national adoption of a peer-to-peer health education model as an intervention for tobacco use but not for nutrition and physical activity choices.

Mise en œuvre d'un modèle d'éducation en santé axé sur l'intervention des pairs aux Émirats arabes unis : lutter contre les comportements à risque des adolescents expatriés

RÉSUMÉ La consommation de tabac parmi les jeunes est en augmentation aux Émirats arabes unis, et le pays se classe au quinzième rang mondial pour la prévalence du diabète de type 2. Les expatriés constituent une majorité de la population, ce qui fait d'eux un sous-ensemble important à étudier. Notre objectif consistait à déterminer si une intervention éducative serait efficace dans ce contexte culturel. Nous avons mis au point deux ateliers de santé organisés par des pairs et portant sur le tabagisme d'une part, et sur la nutrition et l'activité physique d'autre part. Dix-huit classes d'établissements privés à Abou Dhabi se sont vues attribuées I'un des deux ateliers thématiques susmentionnés. Des sondages ont été menés avant et après les ateliers afin d'évaluer l'efficacité de l'intervention. L'atelier sur le tabagisme a conduit à une amélioration significative des modifications de comportement $(p<0,05)$. L'atelier sur la nutrition et l'activité physique a permis une baisse de la satisfaction des participants concernant leurs niveaux personnels d'activité. Cette étude fournit des arguments en faveur de l'adoption d'un modèle d'éducation par les pairs comme intervention de lutte contre le tabagisme, mais pas pour les choix liés à la nutrition et l'activité physique.

${ }^{1}$ University of Oklahoma School of Community Medicine, Tulsa, United States of America; ${ }^{2}$ New York University School of Medicine, New York, United States of America (Correspondence to: Leena W. Asfour: leena.asfour@med.nyu.edu). ${ }^{3}$ Departments of Pediatrics and Environmental Medicine; ${ }^{4}$ Department of Population Health, New York University School of Medicine; ${ }^{6}$ Public Health Research Center, Global Institute of Public Health, New York University, New York, United States of America. *Authors contributed equally.

Received: 11/9/15; accepted: 20/11/16 


\section{Introduction}

As the prevalence of noncommunicable diseases continues to rise, health care providers and policy-makers have begun to seek preventive measures. Prevention can be as simple as healthy lifestyle choices regarding tobacco use, diet and physical activity (1). However, these choices are heavily influenced by habits formed at very young ages (2). By targeting teenagers and educating them about the consequences of their lifestyle choices, we may be able to combat major behavioural contributors to the most burdensome health conditions. To date, however, school-based health education has not been established as a global norm. School systems in many Gulf Cooperation Council countries have yet to incorporate comprehensive health curricula as part of students' academic experience (3). In the United Arab Emirates, high schools are not mandated to provide any sort of health education to their students (4). In another study using the same cohort studied here, we identified not only a gap in health education but also an inefficacy of anti-tobacco laws and campaigns (5). In light of these findings, health education has unexplored potential.

We chose the focus of our health workshops to be topics that are the most salient to the population of the United Arab Emirates, namely tobacco use, physical activity and nutrition. Although tobacco consumption in high- and middle-income countries has recently decreased, the Middle East has an increasing prevalence of tobacco use, especially among youth $(6,7)$. In this cohort, 39\% of males had already tried cigarette smoking, at an average age of $12-13$ years (5). Furthermore, 39\% of males report using waterpipe tobacco (shisha) and 7\% report using dokha, a type of tobacco common around the Persian Gulf (5). Amongst females in this cohort, $19 \%$ had tried cigarette smoking, $37 \%$ had tried waterpipe tobacco and $7 \%$ had tried dokha at an average age of $11-12$ years (5).

With $18.8 \%$ of the population living with type II diabetes, the United Arab Emirates is ranked 15th in the world for prevalence of this condition (8). The rise in obesity and sedentary lifestyles along with increasing access to unhealthy food options has contributed to the increased prevalence (9). Even with government mandated initiatives to fight the increase in childhood obesity, the dramatic change in lifestyle over the past 40 years has developed a culture of poor eating habits and physical inactivity that are strongly embedded in the daily routine of the average resident (10). While our study focuses on expatriate youth, these data are relevant as the culture and environment of the United Arab Emirates influence the lifestyle decisions of the large expatriate community. Moreover it has been reported that our cohort of teens consumed a large amount of sugary drinks each day and are not physically active on a daily basis. Many students also self-reported eating too much or too little and going to extreme measures to lose weight (5).

The purpose of this study was to evaluate the efficacy of peer-mediated health education in schools with predominantly expatriate youth in Abu Dhabi, United Arab Emirates. According to the last census information available, just over $89 \%$ of the population were identified as non-nationals (11). As this is such a large majority of the population, it is an important subset for us to study and understand, especially if current migration trends continue (12). Research in other countries has shown that peer-to-peer education models which train young people to teach students are highly effective (13). As a result, peer-mediated models have seen increased utilization for topics in health education (14). A study conducted in the United Arab Emirates with 12th grade students found that a peer-to-peer workshop on HIV/AIDS was effective in improving knowledge, attitudes and perceptions of the condition (15). We decided to use this model in designing our school-based intervention. To supplement our study of intervention effectiveness on the health topics specifically, we also decided to elicit feedback from the students about the peer-to-peer model. No other studies to date have tested a health education intervention for tobacco use, nutrition and physical activity in the United Arab Emirates at the high school level.

\section{Methods}

\section{Study design}

A pre-workshop survey was administered to our cohort to establish a baseline for knowledge, attitudes and behaviours regarding tobacco use, nutrition and physical activity. The cohort was split and given either a nutrition and physical activity workshop or a tobacco workshop. A post-workshop survey was administered. We evaluated the efficacy of each workshop by comparing the pre- and post-survey questions pertinent to each workshop (i.e. tobacco or nutrition and physical activity) and using the responses of the other workshop group as a control.

We focused on 9th graders because the literature suggested that smoking tobacco becomes a highly relevant topic around this age. As noted earlier, 39\% of males and 19\% of females of this cohort had already tried cigarette smoking (5).

\section{Data collection and workshop implementation}

The cohort consisted of 9th grade students from 5 private high schools distributed throughout the city of Abu Dhabi. Schools whose curricula were not taught in English were excluded in order to ensure the students had sufficient English reading and writing skills to complete the surveys accurately (all 36 public schools in Abu Dhabi with a 9th grade teach in Arabic and 
were not included). According to the Abu Dhabi Education Council website there are 80 private schools in the $\mathrm{Abu}$ Dhabi Emirate that have a 9 th grade. Of these, 18 teach their curricula in Arabic, leaving 62 that do not teach in Arabic. We called these schools at random. The first 5 that answered our phone calls and did not have health curricula were included in the study. After calling 11 schools we had found the appropriate number of classes meeting our criteria and willing to work our study into their class schedule. We would like to point out that only 2 of the 11 schools we contacted already had health curricula. Each school had a student body primarily composed of students from a Middle Eastern or North African (MENA) origin. Upon reaching an agreement with each partner school, both parental and minor consent forms were distributed and returned before scheduling the preworkshop survey. Of the possible study cohort, $99 \%$ of the students agreed to participate in the study. Those who did not return the consent forms were allowed to study in a separate classroom during the lesson and surveys.

The pre- and post-workshop surveys were completely anonymous and comprised questions from the World Health Organization (WHO) Global Youth Tobacco Survey (GYTS) and the Centers for Disease Control Youth Risk Behavior Surveillance System. The WHO had previously administered the GYTS in the United Arab Emirates in 2001 and 2005, yet failed to address more-regional varieties of tobacco that students might readily encounter.

After administration of the preworkshop survey, a peer-mediated tobacco or nutrition and physical activity workshop was conducted. The tobacco workshop was organized into subsections that focus on the following: the importance of talking about tobacco as a teenager, what tobacco is, long and short term effects of tobacco smoking on the human body, different types of tobacco smoking that are common in the region, influences on teen smoking, and the benefits of tobacco cessation. An analogous nutrition and physical activity workshop was also implemented, following the same curriculum pattern as listed above. The focus of each workshop was to provide accurate and useful information that students could use to make healthy decisions and to complete exercises that improved attitudes towards healthy lifestyles. The workshop materials consisted of a brief workbook and several props to make the workshop more interactive. PowerPoint presentation was not used. Two of the authors (LWA and ZDS), both university students who were trained and had experience as health educators and curriculum designers, designed and taught the workshops. Each workshop lasted the duration of 1 class period, generally 45 minutes.

We taught the workshops to a total of 18 segregated classrooms ( 10 female, 8 male). Each classroom was randomly assigned either the tobacco or the nutrition and physical activity workshop (5 female tobacco workshops, 5 female nutrition and physical activity workshops, 4 male tobacco workshops, and 4 male nutrition and physical activity workshops). The post-workshop survey was administered approximately 2-3 weeks after the workshop.

The Institutional Review Board of New York University Abu Dhabi approved all steps of the methodology.

\section{Statistical analysis of survey research}

All survey data were compiled into a database, and letter choices were converted according to our survey codebook using Python. Where relevant, letter choices were ranked based on which responses had the best health outcomes with the best response starting at zero. No sample size calculations were performed.

To assess the impact of the workshops on the participants' beliefs on tobacco use or nutrition and physical activity, the statistical software STATA was used to calculate ordinal logistic regressions (proportional odds models) on responses for 29 questions. There were 22 questions mapped to the tobacco workshop and 7 to the nutrition and physical activity workshop. The preworkshop data acted as the baseline for the regression, and the post-workshop data were monitored for change using this baseline. Each dependent variable (survey question) was controlled for by several independent variables - age, sex and school attended. Because the post-workshop surveys were identical for each workshop group, the postworkshop data for one workshop group acted as the control for the other. For example, we could examine changes in a certain attitude on tobacco use in the nutrition and physical activity group and the tobacco group. The comparison identifies whether the information in the tobacco workshop was independently associated with the change or whether another factor was responsible. Odds ratios and 95\% confidence intervals were calculated to interpret the coefficient of the ordinal logistic regression.

For the 4 yes or no questions assessing the efficacy of the peer-to-peer model, which were only included in the post-workshop survey, the statistical software $R$ was used for performing simple binomial tests on response frequencies.

\section{Results}

\section{Description of intervention cohort}

The sample consisted of 439 respondents: $46.5 \%$ male and $53.5 \%$ female. The average age was 13.9 years $(\sigma=0.76)$. The average weekly disposable income of the students was AED 94.41 (\$US 25.70).

\section{Analyses of workshop effectiveness}

We analysed 439 completed pre-surveys and 394 completed post-surveys, 
with missing data accounted for by absence from school on the date of the workshop or survey. Compared to the cohort's baseline responses in the preworkshop survey, the tobacco workshop effected change in 12 questions related to attitudes and perceptions of tobacco use. The specific questions, ordinal logit coefficients and odds ratios are outlined in Table 1. The answer choices within a question were ranked from healthiest to least healthy. The healthiest response was scored as 0 , and the score increased by 1 for the answer choices based on their health ranking within a question. As a result of this ranking method, a negative ordinal logit coefficient demonstrates change towards a healthier perception, attitude or knowledge base. The tobacco workshop was also significantly associated with changes in 2 nutrition and physical activity-related questions in bivariate analyses. The changes in all cases were in the desired direction, namely a healthier outcome.

When compared with the baseline, the nutrition and physical activity workshop was associated with a change in response to 1 of the 7 nutrition and physical activity-related questions, but did not affect any of the tobacco related questions. Table 1 includes the 1 nutrition and physical activity question affected along with the ordinal logistic regression coefficient and corresponding odds ratio.

Finally, we found that overall the cohort felt that the peer-to-peer workshop model was informative, relatable, worth sharing with family and friends, and recommendable to friends. The majority of students in both the tobacco and the nutrition groups responded positively to 4 questions that evaluate how the cohort felt about the peer-topeer model (Table 2). For the 2-sided binomial tests $P<0.01$, meaning that the respondents significantly chose "yes" to each of the 4 questions.
We did not evaluate our data for differences between male and female responses.

\section{Discussion}

Overall, the tobacco workshop was effective in improving knowledge, attitudes and perceptions about tobacco use, resulting in improvement on 12 questions. The nutrition and physical activity workshop was not effective in improving knowledge, attitudes and perceptions of nutrition and physical activity; it only resulted in a decrease in the teenagers' level of satisfaction with their physical activity. The success of the tobacco workshop may be attributed to the fact that tobacco use is a more salient topic at this stage in life than nutrition and physical fitness. It may also be because the gap in knowledge about tobacco use is greater than it is for eating healthily and exercising regularly. Many students were shocked to learn that shisha and dokha presented health risks just as serious as those of cigarette smoking. On the other hand, only 3 out of 10 students had not received advice about leading a healthy lifestyle (5). This suggests that another workshop or another method of disseminating information should be developed as the cohort did reveal unhealthy lifestyle habits.

An examination of the questions that were not significantly impacted by the workshops reveals a number of important findings. The questions "If one of your best friends offered you shisha, would you smoke it?" and "Do you agree or disagree with the following: I think I might enjoy smoking shisha?" were significantly impacted by the tobacco workshop while the same questions about "tobacco products" and "dokha" were not. This appears to confirm that shisha was thought of as a harmless social activity and that the tobacco workshop successfully corrected this common misconception. Other questions that did not show significant changes may be attributed to the fact that they did not have many undesirable potential responses or to a weakness in the workshop content.

The 4 questions that probed the students' opinions on the model we used confirmed that the peer-to-peer model was popular and effective in this cultural setting. An overwhelming majority of students stated that they plan on using something they learned in their workshop to make a future decision regarding their health, which hits at the crux of the goals for health education for adolescents: prevention of participation in risky behaviours that increase the risk for noncommunicable diseases later in life. Engagement in the health education workshop is crucial to its success and it is encouraging that the majority of students would not only recommend a similar workshop to friends or family but would also share something that they have learned, further increasing the audience and power of the workshop.

\section{Evaluation and improvements}

Because self-reporting was the method used to collect data, the results are subject to social desirability bias. Despite assuring our participants of the confidentiality of their survey responses, the cultural setting of the United Arab Emirates may have prevented some from reporting honestly. It should be noted that the surveys used were not tested for reliability or validity in this cultural context.

There may also be some spillover effects between the workshops. The tobacco workshop, for example, was able to affect 2 nutrition and physical activity questions which were not addressed in that workshop. We hypothesize that learning about how tobacco use impacts human health led to students thinking about healthier behaviours in general.

Our cohort (exclusively 9th graders in private schools in Abu Dhabi whose language of instruction is English) limits the scope of the study. Differences 
with public schools, schools with Arabic as the language of instruction, other grade levels, and schools in different parts of the United Arab Emirates may be notable. Additionally, our study did not assess changes in behaviour owing to the short time between the baseline and post-workshop surveys. Due to the relatively small sample size, we recognize that our attempts to randomize may have had limited effectiveness in balancing the 2 workshop groups.

\section{Future studies}

The sample in this study did not take into account the Emirati perspective, since we included schools predominantly for expatriates rather than local public schools. Future studies on the effectiveness of peer-mediated health workshops should target local populations in their native language. Moreover, workshops on other health topics should be created using the peer-to-peer model and tested to see if they are also effective in this environment.

\section{Conclusion}

By creating, implementing and evaluating a peer-mediated health education model among expatriate students in the United Arab Emirates, we have shown that simple, cost-effective interventions can have a significant impact. Tobacco

\begin{tabular}{|c|c|c|c|}
\hline Question & Workshop & $\begin{array}{l}\text { Ordinal logit coefficient } \\
\text { (SE) }\end{array}$ & Odds ratio (SE) \\
\hline \multirow{2}{*}{$\begin{array}{l}\text { Do you agree or disagree with the following: "I think I } \\
\text { might enjoy smoking shisha." }\end{array}$} & $\mathrm{N} / \mathrm{PA}$ & $0.200(0.165)$ & $1.220(0.201)$ \\
\hline & Tobacco & $-0.525(0.168)^{* * *}$ & $0.592(0.099)^{* * *}$ \\
\hline \multirow{6}{*}{$\begin{array}{l}\text { Do you think smoking shisha helps people feel more } \\
\text { comfortable or less comfortable at celebrations, parties, } \\
\text { or in other social gatherings? } \\
\text { Do you think smoking dokha helps people feel more } \\
\text { comfortable or less comfortable at celebrations, parties, } \\
\text { or in other social gatherings? } \\
\text { Once someone has started smoking tobacco, do you } \\
\text { think it would be difficult for him or her to quit? }\end{array}$} & $\mathrm{N} / \mathrm{PA}$ & $0.126(0.166)$ & 1.130 (0.189) \\
\hline & Tobacco & $-0.336(0.163)^{* *}$ & $0.715(0.117)^{* *}$ \\
\hline & $\mathrm{N} / \mathrm{PA}$ & $-0.066(0.167)$ & $0.936(0.156)$ \\
\hline & Tobacco & $-0.345(0.166)^{* *}$ & $0.708(0.118)^{* *}$ \\
\hline & $\mathrm{N} / \mathrm{PA}$ & $0.019(0.172)$ & $1.020(0.175)$ \\
\hline & Tobacco & $-0.347(0.172)^{* *}$ & $0.707(0.121)^{* *}$ \\
\hline \multirow{2}{*}{$\begin{array}{l}\text { Once someone has started smoking shisha, do you think } \\
\text { it would be difficult for him or her to quit? }\end{array}$} & N/PA & $0.199(0.166)$ & $1.220(0.203)$ \\
\hline & Tobacco & $-0.594(0.167)^{* * *}$ & $0.655(0.134)^{* * *}$ \\
\hline \multirow{2}{*}{$\begin{array}{l}\text { Once someone has started smoking dokha, do you think } \\
\text { it would be difficult for them to quit? }\end{array}$} & N/PA & $0.168(0.170)$ & $1.183(0.201)$ \\
\hline & Tobacco & $-0.284(0.165)^{*}$ & $0.752(0.124)^{*}$ \\
\hline \multirow{2}{*}{$\begin{array}{l}\text { Do you think the smoke from other people's tobacco } \\
\text { smoking is harmful to you? }\end{array}$} & N/PA & $-0.072(0.171)$ & $0.930(0.159)$ \\
\hline & Tobacco & $-0.813(0.183)^{* * *}$ & $0.440(0.081)^{* * *}$ \\
\hline \multirow{2}{*}{$\begin{array}{l}\text { Do you think the smoke from other people's shisha } \\
\text { smoking is harmful to you? }\end{array}$} & $\mathrm{N} / \mathrm{PA}$ & $-0.028(0.164)$ & $0.972(0.159)$ \\
\hline & Tobacco & $-0.695(0.168)^{* * *}$ & $0.499(0.084)^{* * *}$ \\
\hline \multirow{2}{*}{$\begin{array}{l}\text { Do you think the smoke from other people's dokha } \\
\text { smoking is harmful to you? }\end{array}$} & $\mathrm{N} / \mathrm{PA}$ & $0.031(0.170)$ & $1.030(0.175)$ \\
\hline & Tobacco & $-0.516(0.174)^{* * *}$ & $0.597(0.104)^{* * *}$ \\
\hline \multirow{2}{*}{$\begin{array}{l}\text { At any time during the next } 12 \text { months do you think you } \\
\text { will use any form of tobacco? }\end{array}$} & $\mathrm{N} / \mathrm{PA}$ & $-0.124(0.188)$ & $0.884(0.167)$ \\
\hline & Tobacco & $-0.384(0.194)^{* *}$ & $0.681(0.132)^{* *}$ \\
\hline \multirow{2}{*}{$\begin{array}{l}\text { If one of your best friends offered you shisha, would you } \\
\text { smoke it? }\end{array}$} & $\mathrm{N} / \mathrm{PA}$ & $0.111(0.169)$ & $1.110(0.189)$ \\
\hline & Tobacco & $-0.433(0.177)^{* *}$ & $0.648(0.115)^{* *}$ \\
\hline \multirow[t]{2}{*}{ Do you think smoking tobacco is harmful to your health? } & $\mathrm{N} / \mathrm{PA}$ & $0.008(0.194)$ & $1.010(0.196)$ \\
\hline & Tobacco & $-0.595(0.217)^{* * *}$ & $0.551(0.119)^{* * *}$ \\
\hline \multirow{2}{*}{$\begin{array}{l}\text { How important do you think nutrition is to maintaining a } \\
\text { healthy lifestyle? }\end{array}$} & N/PA & $0.139(0.179)$ & $1.150(0.206)$ \\
\hline & Tobacco & $-0.554(0.192)^{* * *}$ & $0.575(0.111)^{* * *}$ \\
\hline \multirow{2}{*}{$\begin{array}{l}\text { On an average school day, how many hours do you } \\
\text { watch TV? }\end{array}$} & $\mathrm{N} / \mathrm{PA}$ & $-0.069(0.161)$ & $0.933(0.150)$ \\
\hline & Tobacco & $-0.314(0.160)^{* *}$ & $0.730(0.117)^{* *}$ \\
\hline \multirow{2}{*}{$\begin{array}{l}\text { Are you currently satisfied with your level of physical } \\
\text { activity? }\end{array}$} & N/PA & $0.332(0.163)^{* *}$ & $1.390(0.228)^{* *}$ \\
\hline & Tobacco & $0.157(0.163)$ & $1.17(0.190)$ \\
\hline
\end{tabular}

The $n$ values used in the logistic ordinal regressions were s: pre-N/PA=230, pre-tobacco $=209$, post- $\mathrm{N} / \mathrm{PA}=196$, post-tobacco $=198$.

$S E=$ standard error.

$N / P A=$ nutrition and physical activity.

${ }^{*} P<0.1$.

${ }^{* *} P<.05$.

*** $P<0.07$. 


\begin{tabular}{|c|c|c|c|c|}
\hline \multirow[t]{3}{*}{ Question } & \multirow{2}{*}{\multicolumn{2}{|c|}{$\begin{array}{c}\text { Tobacco } \\
(n=198) \\
\text { Yes }\end{array}$}} & \multirow{2}{*}{\multicolumn{2}{|c|}{$\begin{array}{c}\text { N/PA } \\
(n=196) \\
\text { Yes }\end{array}$}} \\
\hline & & & & \\
\hline & No. & $\%$ & No. & $\%$ \\
\hline $\begin{array}{l}\text { Do you think that college students are more relatable (to yourself) than adults or } \\
\text { medical professionals? }\end{array}$ & 125 & 63 & 118 & 60 \\
\hline Would you recommend this type of workshop to your friends? & 164 & 83 & 129 & 66 \\
\hline $\begin{array}{l}\text { Do you plan on sharing anything you learned in the workshop with friends and/or } \\
\text { family? }\end{array}$ & 154 & 78 & 125 & 64 \\
\hline $\begin{array}{l}\text { Do you think that you will use any of the information you learned in the workshop } \\
\text { to make future decisions about your health? }\end{array}$ & 164 & 83 & 137 & 70 \\
\hline
\end{tabular}

$N / P A=$ nutrition and physical activity.

use is a serious issue for young adults in the Middle East and even minimal education can have an impact on their perceptions of this life threatening habit. We believe that such an approach is a promising method for producing positive changes in lifestyle decisions among the youth in Abu Dhabi, and possibly elsewhere in the United Arab Emirates. Moreover, one might anticipate that healthy habits formed early on will continue into adulthood, directly addressing the behaviours that increase the risk for cancer, heart disease, stroke, diabetes, etc. It is our hope that these types of grass roots initiatives can be used to enhance the efficacy of legislation and enforcement of laws designed to promote a healthier lifestyle.

This type of model is also self-sustaining in that university students can teach high school students at no cost.
Peer education not only equips the high school students with the knowledge they need to make healthy decisions about their life but also empowers student teachers to be agents of change in their own communities and gain excellent communication skills.

Funding: This study was funded by New York University Abu Dhabi.

Competing interests: None declared.

\section{References}

1. Beaglehole R, Bonita R, Horton R, Adams C, Alleyne G, Asaria $\mathrm{P}$, et al. Priority actions for the non-communicable disease crisis. Lancet. 2011;377(9775):1438-47. PMID: 21474174

2. Jones AM. Health, addiction, social interaction and the decision to quit smoking. J Health Economics. 1994;13(1):93-110.

3. Buente M, Hashemi AA, Moujaes CN, Samman, H. GCC school health programs. Health and wellness through early intervention. Booz and Company; 2010.

4. Godwin SM. Globalization, education, and Emiratisation: a study of the United Arab Emirates. Electronic J Information Systems in Developing Countries. 2006;27(1):1-14.

5. Asfour LW, Stanley ZD, Weitzman M, Sherman SE. Uncovering risky behaviors of expatriate teenagers in the United Arab Emirates: a survey of tobacco use, nutrition and physical activity habits. BMC Public Health. 2015;15:944. PMID: 2639975

6. Jha P, Chaloupka FJ, Moore J, et al. Tobacco addiction. In: Jamison DT, Breman JG, Measham AR, eds. Disease control priorities in developing countries. Washington DC: World Bank, 2006: Chapter 46.

7. Tamim H, Al-Sahab B, Akkary G, Ghanem M, Tamim N, El Roueiheb $Z$, et al. Cigarette and nargileh smoking practices among school students in Beirut, Lebanon. Am J Health Behav. 2007;31:56-63. PMID:17181462

8. Whiting DR, Guariguata L, Weil C, Shaw J. IDF diabetes atlas: global estimates of the prevalence of diabetes for 2011 and 2030. Diabetes Res Clin Pract. 2011;94(3):311-21. PMID:22079683
9. Musaiger AO. Diet and prevention of coronary heart disease in the Arab Middle East countries. Med Princ Pract. 2002;11(Suppl. 2):9-16. PMID:12444306

10. Jayakumary M, Jayadevan S, Ranade AV, Mathew E. Prevalence and pattern of dokha use among medical and allied health students in Ajman, United Arab Emirates. Asian Pac J Cancer Prev. 2010;11:1547-9. PMID:21338195

11. Methodology of estimating the population in UAE. Abu Dhabi: United Arab Emirates National Bureau of Statistics; 2011 (http://www.uaestatistics.gov.ae/ReportPDF/Population Estimates 2006 - 2010.pdf, accessed 15 Nov, 2014).

12. Shah NM. Arab migration patterns in the Gulf. In: Arab migration in a globalized world. Geneva: International Organization for Migration and League of Arab States; 2004:91-113 (http:// publications.iom.int/system/files/pdf/arab_migration_globalized_world.pdf, accessed 19 April 2017).

13. Damon W. Peer education: the untapped potential. J Appl Dev Psychol. 1984;5(4):331-43.

14. Backett-Milburn K. Understanding peer education: insights from a process evaluation. Health Educ Res. 2000;15(1):85-96. PMID:10788205

15. Barss P, Grivna M, Ganczak M, Bernsen R, Al-Maskari F, El Agab $H$, et al. Effects of a rapid peer-based HIV/AIDS educational intervention on knowledge and attitudes of high school students in a high-income Arab country. J Acquir Immune Defic Syndr. 2009;52.1:86-98. PMID:19590431 